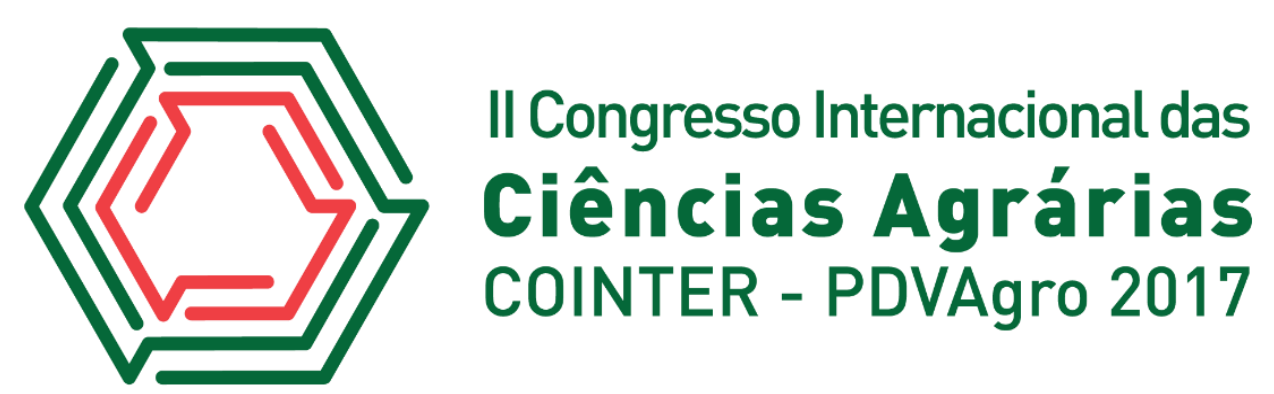

\title{
MÉTODO FAMACHA E CONTAGEM DE HEMATÓCRITO EM CAPRINOS SEM PADRÃO RACIAL DEFINIDO
}

Apresentação: Pôster

Jesane Alves de Lucena ${ }^{1}$; Vitor Lucas de Lima Melo²; Waleska Nayane Costa Soares ${ }^{3}$; Ramom Duarte Nogueira $^{4}$; Hilton Felipe Marinho Barreto ${ }^{5}$

\section{Introdução}

Entre os principais problemas para a expansão da caprinocultura no semiárido do Nordeste estão as endoparasitoses gastrintestinais. Estudos mostram que animais parasitados podem apresentar sinais de anemia, apatia, hipoproteinemia, edema submandibular e nos casos mais severos pode ocorrer a morte do animal. O grau de anemia apresentada pelo animal pode ser determinado utilizando-se o método laboratorial hematócrito e o prático Famacha. Segundo Molento et al., (2004), o Famacha é realizado através da comparação de diferentes tonalidades de cor da conjuntiva, desde o vermelho robusto até o branco pálido, representada com números de $1 \mathrm{a}$ 5. A aplicação do método Famacha em caprinos deve considerar alguns critérios específicos. A coloração da conjuntiva de caprinos sadios tem menor intensidade quando comparada com ovinos sadios. A exposição da mucosa dos caprinos deve esperar 6 a 8 segundos para fazer a leitura do grau de anemia (MOLENTO, 2007). O micro-hematócrito representa um dos mais importantes exames da série vermelha do sangue. É um exame rápido, de boa reprodutibilidade e preciso, que exige pequena quantidade de sangue para seu processamento. O objetivo desse trabalho foi utilizar os dois métodos para identificar a anemia em caprinos sem padrão racial definido (SPRD) e correlacionar o resultado entre eles.

\section{Fundamentação Teórica}

O controle da verminose gastrintestinal em pequenos ruminantes tem sido avaliado por diferentes técnicas. Em função dos altos índices de resistências dos parasitos aos diferentes princípios ativos, novas alternativas de controle vem sendo estudadas para poder diminuir a necessidade de utilização dos anti-helmínticos. O uso de estratégias que não necessitem de

\footnotetext{
${ }^{1}$ Professora titular do centro de ciências agrárias, UFERSA, jesane@ufersa.edu.br

${ }^{2}$ Zootecnista, vitor_Ilm@hotmail.com

${ }^{3}$ Graduanda em zootecnia, UFERSA, walesca_nayane@hotmail.com

${ }^{4}$ Graduando em Medicina Veterinária, UFERSA, ramomcem2013@hotmail.com

${ }^{5}$ Zootecnista e Docente do IFRN - Campus Apodi, felipe.barreto@ifrn.edu.br
} 
desverminações massivas são necessárias na tentativa de retardar o aparecimento de resistência parasitária (SOTOMAIOR et al. 2007). O método FAMACHA (Faffa Malan Chart) foi lançado em 1997 com o objetivo de identificar individualmente os animais que necessitam ou não serem tratados contra Haemonchus contortus (MOLENTO,2004). O exame é feito por meio de uma avaliação visual para definir a coloração da conjuntiva frente a um cartão de cores que foi preestabelecido com auxílio de computação gráfica e que acompanha a técnica. A principal característica do método Famacha é a identificação de animais resistentes e resilientes no rebanho, sendo possível a seleção de animais que não necessitam receber tratamento antiparasitário (MOLENTO et al. 2004). A indicação de tratamento pelo cartão é baseada unicamente na coloração da conjuntiva e quanto maior o grau Famacha maior a urgência de tratamento. E a coloração da conjuntiva representa o valor de hematócrito. Segundo o mesmo autor os valores de hematócrito correspondentes ao grau Famacha são; grau 1 (28\% e valores acima), grau 2 (23 - 27\%), grau 3 (18$22 \%)$, grau $4(13-17 \%)$ e grau 5 (12\% e valores abaixo). O controle da verminose gastrintestinal em pequenos ruminantes tem sido avaliado por diferentes técnicas. Em função dos altos índices de resistências dos parasitos aos diferentes princípios ativos, novas alternativas de controle vem sendo estudadas para poder diminuir a necessidade de utilização dos anti-helmínticos. O uso de estratégias que não necessitem de desverminações massivas são necessárias na tentativa de retardar o aparecimento de resistência parasitária (SOTOMAIOR et al. 2007).A classificação utilizando somente os dados do Famacha, pode representar animais tanto resistentes quanto resilientes (SOTOMAIOR et al. 2007).O método Famacha apresenta como principal benefício a redução do número de tratamentos, pois os animais são avaliados individualmente e somente alguns são desverminados, baixando a pressão de seleção do $H$. contortus para a resistência aos antihelmínticos (VAN WYK, 2002). No entanto, o FAMACHA tem ação limitada na interpretação do grau de parasitismo quando outros parasitos além do Haemonchus estão presentes em grandes proporções no rebanho (BATH et al. 2001; SOTOMAIOR et al. 2009; BATH; VAN WYK, 2009; OLIVEIRA et al. 2011). Nem sempre o grau FAMACHA corresponderá ao seu valor de referência no hematócrito. O método deve ser utilizado em conjunto com outra técnica de diagnóstico de parasitose (ABRAÃO et al. 2010). Bath et al (2001), afirmaram que a subjetividade da avaliação pode permitir a classificação equivocada de animais e consequente menores valores de correlação. MOLENTO et al. (2004) relatam a existência de animais considerados discrepantes, cuja conjuntiva ocular não apresenta a coloração relativa ao grau FAMACHA compatível com seu valor de hematócrito. Por sua vez o hematócrito representa um dos mais importantes exames da série vermelha do sangue. É um exame rápido, de boa reprodutibilidade e preciso, que exige pequena 
quantidade de sangue para seu processamento. $\mathrm{O}$ hematócrito corresponde ao volume ocupado pelos eritrócitos contidos numa certa quantidade de sangue total.

\section{Metodologia}

O trabalho foi realizado em uma propriedade rural localizada no município de Baraúna/RN. Foram realizadas visitas periódicas para avaliação do grau de anemia pelos métodos Hematócrito (laboratorial) e Famacha (prático). Participaram da pesquisa 81 caprinos adultos sem padrão racial definido (SPRD), criados em sistema semi-intensivo onde passavam a maior parte do tempo na caatinga. O período de avaliação ocorreu entre dezembro/2014 e Junho/2015. As amostras de sangue foram coletadas por punção da veia jugular externa, em tubos vacutainer com anticoagulante, para obtenção do valor do hematócrito. Após a colheita, os tubos foram enviados ao laboratório de Parasitologia da Universidade Federal Rural do Semi-Árido (UFERSA). A determinação da anemia pelo Famacha foi realizada com a utilização do cartão guia que acompanha o método.

\section{Resultados e Discussões}

Os resultados mostram a identificação de anemia pelos dois métodos nos animais em estudo. Na tabela 1 encontram-se os resultados obtidos pelo Famacha e pelo Hematócrito (laboratorial), utilizado em caprinos adultos sem padrão racial definido.

Tabela 1 - Correlação entre o método Famacha e o Hematócrito (laboratorial) em caprinos adultos sem padrão racial definido $(\%)$

\begin{tabular}{ccc}
\hline NÚMERO DE ANIMAIS & FAMACHA (grau) & Hematocrito $(\%)$ \\
\hline 18 & 1 & 22,2 \\
17 & 2 & 20,99 \\
17 & 3 & 20,99 \\
16 & 4 & 19,75 \\
13 & 5 & 16,05
\end{tabular}

Observa-se que os animais classificados com graus 1 e 2 pelo Famacha não necessitam de vermifugação, entretanto apresentaram baixo valor de hematócrito. O grupo de grau 3 apresentou compatibilidade entre hematócrito e valor referência indicado pelo Famacha (20,99\% X 18 a 22\%). É o primeiro nível do grau de anemia que deve ser vermifugado. Pelo método Famacha os animais 
que apresentaram graus 4 e 5 também devem ser vermifugados. Nesses grupos o hematócrito foi alto em relação ao hematócrito indicado pelo Famacha. Segundo Nolli et al., (2008), trabalhando com ovinos, correlacionaram os resultados obtidos pelo método prático e o laboratorial na identificação de anemia. Os autores observaram que os valores de hematócrito laboratorial para os graus 3,4 e 5 não foram adequados em relação aos valores referência do Famacha. Chagas et al., (2007), verificaram que a correspondência entre o grau Famacha e o hematócrito em ovinos (matrizes e cordeiros) variou de $38 \%$ a $93 \%$. Nesta pesquisa, alguns fatores podem ter contribuído para esse resultado. Podemos citar a pouca experiência dos avaliadores no manuseio do cartão Famacha, o número de repetições nos períodos seco e chuvoso, a especificidade da espécie animal e o manejo sanitário e alimentar.

\section{Conclusões}

Nas condições em que o ensaio foi conduzido o método Famacha deve ser utilizado por pessoal treinado e acompanhado de outras técnicas como a contagem de ovos por grama de fezes (OPG).

\section{Referências}

ABRÃO, D. C.; ABRÃO, S.; VIANA, C. H. C.; VALLE, C. R. Utilização do método FAMACHA no diagnóstico clínico individual de haemoncose em ovinos no Sudoeste do Estado de Minas Gerais. RevistaBrasileiraParasitológicaVeterinária, Jaboticabal. v. 19, n. 1, p. 70-72, 2010.

BATH, G. F.; HANSEN, J. W.; KRECEK, R. C.; VAN WYK, J. A.; VATTA, A. F. Sustainable approaches for managing haemoncosis in sheep and goats. Roma: FAO, 2001. 90p.

BATH, G. F.; VAN WYK, J. A. The Five Point Check for targeted selective treatment of internal parasites in small ruminants. Small Ruminant Research, Amsterdam, v. 86, n.1-3, p. 6-13, 2009.

CHAGAS, A. C .S. et al. Método Famacha: Um recurso para o controle da verminose em ovinos. Circular técnica, n. 52, São Carlos-SP. 2007

NOLLI, C. P.; GRECA, S. P.; GARCIA, A Anual da Sociedade B. M.; PEREZ, J. R. Correlação entre método Famacha e contagem de hematócrito em ovinos. $45^{\text {a }}$ Reunião Anual da Sociedade Brasileira de Zootecnia. Lavras-MG. UFLA, 22 a 25 de julho de 2008. Anais.

MOLENTO,M. B. et al. Método Famacha como parâmetro clínico individual de infecção por Haemonchuscontortus em pequenos ruminantes. Ciência Rural, vol 34, p. 1139 - 1145, 2004.

MOLENTO, M. B. Método Famacha: tratamento seletivo no combate ao Haemonchuscontortus em pequenos ruminantes. Milkpoint, Piracicaba, 2007. 7p.

OLIVEIRA, M. V.; MOURA, M. S.; BARBOSA, F. C. Avaliação comparativa do método Famacha, volume globular e OPG em ovinos. PUBVET, Londrina, v.5, n. 7, Ed. 154 , Art. 1039, 2011.

SOTOMAIOR, C. S.; ROSALINSKI'MORAES, F.; SOUZA,F. P.; MILCZEWSKI, V.; 
PASQUALIN, C. A. Parasitoses Gastrintestinais dos Ovinos e Caprinos - Alternativas de Controle. Série Informação Técnica, n. 080. Curitiba: Instituto EMATER, 2009. 36p. 